\title{
A FUNÇÃO DA HISTORIOGRAFIA NA OBRA DE DROYSEN
}

\section{Ana Lucia Mandacaru Lobo*}

Universidade de São Paulo

São Paulo - São Paulo - Brasil

Resenha de: ASSIS, Arthur Alfaix. What is history for? Johann Gustav Droysen and the functions of historiography. Oxford: Berghahn Books, 2014.

What is history for? Johann Gustav Droysen and the functions of historiography, escrito pelo historiador Arthur Alfaix Assis, é fruto de seu trabalho de doutoramento na Universidade de Witten/Herdecke, na Alemanha. O autor por ele pesquisado, Johann Gustav Bernhard Droysen, um dos grandes nomes da historiografia alemã do século XIX, nasceu no dia 6 de julho de 1808, na pequena vila de Treptow, na Pomerânia, e faleceu em 1884, em Berlim. Criador da Escola Prussiana, estabeleceu referências metodológicas, teóricas e estruturais para a pesquisa em história. Em princípio, com algum respaldo na teoria hegeliana, posteriormente, diferenciando-se claramente desta, submetendo todo material das fontes a exames críticos e filológicos, no senso estrito dos termos. Dentre suas obras, destacam-se História de Alexandre, o Grande, publicada em 1833, que veio posteriormente a fazer parte do livro História do

\footnotetext{
* Mestre pelo Programa de Pós-Graduação em História Social da Faculdade de Filosofia, Letras e Ciências Humanas da Universidade de São Paulo/USP, Doutora em História Social pela École Pratique des Hautes Études - Sorbonne, com reconhecimento pela USP e pós-doutoranda no Programa de Pós-Graduação em História Social da Faculdade de Filosofia, Letras e Ciências Humanas da Universidade de São Paulo/USP. E-mail: analobo@me.com
} 
Helenismo, composto por dois volumes, tendo sido o primeiro deles publicado em 1836; História da Política Prussiana, composta por catorze volumes, publicados entre 1855 e 1886, e finalmente, Historik, livro em que apresenta os parâmetros e sistematização da pesquisa e do estudo históricos, e posteriormente, Grundriss der Historik, um resumo explicativo do trabalho anterior de imensa importância, no qual se expõem todos os níveis de procedimentos metodológicos da história enquanto disciplina e enquanto ciência, apresentando de maneira ordenada as diferentes formas de operação historiográfica, a saber: a heurística - Heuristik; a crítica das fontes - Kritik; a interpretação - Interpretation; e a exposição histórica - Topik ou Darstellung. Forma-se, assim, uma valiosa articulação entre metodologia e sistematização histórica, introduzindo no meio científico a ideia da função antropológica da história, excluindo definitivamente qualquer relação com aspectos teológicos.

Neste livro, A. A. Assis parte do princípio de que as formulações sobre teoria da história elaboradas por Johann Gustav Droysen possuem papel relevante no percurso intelectual que virá a culminar com a crítica histórica. Em pleno início do século XIX, suas ideias poderiam ser consideradas não apenas inovadoras como complexas, dado o dinamismo perceptual impresso no conceito de temporalidade, assim como de compreensão e interpretação de um fato histórico. O historiador passa a desempenhar um papel cada vez mais ativo no trabalho de escrita da história, e a percepção subjetiva torna-se parte do processo.

Partindo do pressuposto de que grande parte dos leitores desconhece a obra de Droysen, e com a intenção de resgatar a importância e o valor de seus escritos, o autor visa a situar o leitor dentro de um contexto pleno de especificidades: teorias, textos e conceitos entrelaçam-se ao panorama científico da época, às discussões teóricas dali decorrentes e a outros historiadores, outros métodos.

Breve e denso, assim podemos considerar este livro. Ao longo de quatro capítulos, o autor visa a analisar as funções da historiografia e o impacto do "pensamento histórico", tal como proposto por Droysen, no mundo moderno. Esta análise intenta alcançar a ideia de uma redefinição conceitual da função da historiografia, sobretudo no âmbito didático: "a redefinição do valor prático da história".(p.3)

À semelhança do busto de Jano, o autor inicialmente volta seu olhar para o passado, fazendo breves comentários acerca dos gregos Tucídides e Heródoto, para então deter-se na máxima ciceroniana historia magistra vitae enquanto ponto perene e vital dentro da história da historiografia - e mesmo da crítica histórica - embora questionável sobretudo aos olhos de 
Droysen. Além de Cícero, Diodoro Sícolo, Sima Guang e Flávio Josefo são também citados. E é neste momento que se abre o leque de ideias e conceitos de Droysen acerca da historiografia como veículo de compreensão e aprimoramento que, mormente, leva o ser humano a "pensar historicamente" um conceito de grande envergadura dentro da obra analisada. Em seguida, apresenta ao leitor a visão futura, ou inovadora: o pensamento histórico permitiria ao ser humano compreender o tempo presente através da ação e da reflexão, sem que houvesse, necessariamente, a exigência de fixar-se no passado. Poderíamos dizer que seria algo próximo da reconstrução da já citada frase de Cícero na modernidade, acrescentando a ela, porém, certos aspectos mais dinâmicos e outros mais subjetivos.

O impacto da historiografia dentro da cultura, da sociedade ou da política, as definições da tarefa do historiador dentro de seu tempo, bem como os conteúdos descritivos e atributivos dessa atividade, explicitam-se como objeto e objetivo a serem elucidados pelo autor através da análise dos textos em questão.

Com este fim, uma enorme gama de citações extraídas das obras de Droysen é apresentada ao longo do livro. Em alguns momentos elas são absolutamente pertinentes e esclarecedoras, uma vez que ilustram o panorama então analisado pelo autor, fato que imprime no leitor certa intimidade com as ideias de Droysen. No entanto, ao mesmo tempo que se verifica o domínio que o autor possui sobre o tema - pois percorre um grande número de obras - percebe-se nitidamente o direcionamento do trabalho através da delimitação dos conceitos de história, de historiografia e da tarefa da história. Há uma mobilidade visível, inerente ao modo como o próprio Droysen estrutura sua obra: ora direciona suas ideias para o ser humano de modo geral, ora aos políticos e a política, resvalando em críticas à burocracia, e então retorna ao pensamento histórico, por vezes adentra em aspectos teológicos. Tal mobilidade termina, em alguns momentos, por delinear os conceitos pretendidos com certa ambiguidade, ou mesmo contradição, e tal fato poderia, como o autor bem chama atenção, esgotar da obra de Droysen os seus atributos. Entretanto, destaca-se exatamente o oposto, a saber, o quanto terminam por enriquecê-la.

Droysen nunca esclarece um determinado aspecto de sua teoria sem referirse a todos os outros: seus conceitos metodológicos e epistemológicos trazem implícitas as noções relativas à filosofia da história, seus argumentos didáticos implicam inferências éticas e religiosas, e assim por diante. Muitas vezes Droysen apresenta mais ou menos a mesma ideia usando diferentes termos-chave e introduzindo mudanças tangenciais a temas de maior importância. (p. 5) 
Contrariando a facilidade com que os textos de Droysen são manejados, o modo como o historismo foi abordado pelo autor apresenta-se vago, disperso. Trata-se de um conceito de grande importância na estrutura do pensamento e da teoria da história em Droysen e, apesar disto, é apresentado de modo convencional e superficial. Sua complexidade é deixada de lado, e o autor esquiva-se de seus comprometimentos teóricos e das discussões que envolveram seu emprego dentro da história da historiografia. Alguns desses aspectos chegam a ser citados, mas sem qualquer análise mais profunda, apenas como elementos que apontam onde se localizariam tais questões. Seria muito mais enriquecedor para o leitor poder aceder, com objetividade, à tessitura das discussões que se formaram no final do século XIX: todo o desenvolvimento posterior relativo à teoria da história estará diretamente associado a suas raízes, ou seja, o historismo como referência para a construção do espaço da história enquanto ciência, permitindo diversas discussões, usos, questionamentos e ramificações: Ranke e sua reconstrução narrativa, Droysen e seus princípios científicos para uma metodologia da história, WiIhelm Dilthey, cuja influência kantiana será determinante em seu modo de pensar a história como ciência e interpretação cultural, ${ }^{1}$ Ernst Troeltsch e seu enunciado sobre a crise do historismo, ${ }^{2}$ Nietzsche, que considera irrelevante o movimento historicista, ${ }^{3}$ Benedetto Croce e seu historismo absoluto, ${ }^{4} \mathrm{Karl}$ Popper e seu intento em distinguir historicismo e historismo, empregando ao primeiro a complexidade e retórica alemãs e, ao segundo, a visão e a percepção inglesas ${ }^{5}$ e, para além destes, toda a discussão atual proposta por Alexandre Escudier, Georg Iggers, Benedetto Bravo, Otto G. Oexle, Fulvio Tessitore, Ulrich Muhlack, Jörn Rüsen, os quais apresentam análises bastante diferenciadas sobre o historismo e seu valor para a teoria da história e da historiografia, as quais se entrelaçam muitas vezes com a noção de Bildung alemã, nos levando novamente ao trabalho desenvolvido por tanto por Ranke quanto por Droysen à sua época.

Apesar de não se deter ao compêndio das críticas e das discussões que envolvem o conceito de historismo, o autor não deixa de analisar alguns textos de teoria e metodologia da história, visando a reconstruir a ideia de "pen-

\footnotetext{
DILTHEY, W. Einleitung in die Geisteswissenschaften. [S. l.], [s. n.], 1883.

2 TROELTSCH, E. Die krisis des historismus. Die Neue Rundschau, Berlin, [S. 1.], n. 33, p. 572-590, 1922.

NIETZCHE, F. Vom Nutzen und Nachteil der Historie für das Leben: Unzeitgemässe Betrachtung Stück II. Leipzig: Verlag von E. W. Fritzsch, 1874.

4 CROCE, B. La storia come pensiero e come azione. Bari: Laterza, 1938.

5 POPPER, K. The poverty of historicism. Economica, London, vol. 12, n. 46, 1945, p. 69-89.
} 
samento histórico" e os conceitos que daí se desdobram: interpretação, percepção da realidade, identidade e, finalmente, a própria concepção de Bildung.

Dentro da exposição de extremos que vão das ideias de Ranke às de Nietzsche, ou no extremo que vai do isolamento do fato histórico ao pragmatismo historiográfico, Droysen é posicionado entre um e outro. Por conta disto - dessa apresentação panorâmica da época e de seus diferentes autores - vários elementos são destacados com o objetivo de apresentar ao leitor certos aspectos da teoria da história que deles derivariam, e, com isso, as referências metodológicas e teóricas que fundamentaram as ideias de Droysen são expostas de modo mais detalhado: "fonte para orientação cultural, moral ou política, desde que deslocada para uma atmosfera devidamente temporalizada e historicizada" (p. 3).

A originalidade dos textos de Droysen sobre a compreensão da genealogia do tempo presente é um dos fios condutores para o desenvolvimento do livro. O autor se debruça sobre o conceito de helenismo - denominação e conceito cunhado por Droysen - não para compreender o helenismo em si, mas sim para analisar seu desdobramento dentro da obra de Droysen como um todo, com especial atenção à ideia de liberdade enquanto resultado de um prolongamento do processo histórico. Fundamentalmente, ao expor a importância dos conceitos de "pensamento histórico", "compreensão" e "Bildung", Droysen não apenas desenvolveu novos conceitos de metodologia e didática como também elaborou um potencial intelectual de defesa contra o então cientificismo da época. A postura crítica de Droysen, a qual enfatiza a importância do sentido de "Geist" e que se contrapõe ao materialismo histórico, é pormenorizadamente revelada: o materialismo histórico seria, aos olhos de Droysen, uma ameaça à liberdade, uma tentativa de privação da percepção da transcendência. Nesse processo, distinguem-se dois conceitos fundamentais da teoria, que seriam a "explanação" (Erklären) e a "compreensão" (Verstehen).

Droysen não rejeita o fato de que alguns historiadores se utilizassem de métodos quantitativos. Mas ele salienta que tais métodos possuem, na melhor das hipóteses, um valor auxiliar para a pesquisa histórica, haja vista que, sozinhos, jamais poderiam revelar a historicidade dos fenômenos investigados. (p. 129)

Quanto à História da política prussiana, composta por quatorze volumes publicados no período que vai de 1855, data do primeiro volume, a 1886, como último volume publicado como obra póstuma, trata-se de uma obra de grande envergadura, resultado do envolvimento pessoal de Droysen com a política da época e com a tentativa de aplicação do "pensamento histórico" para compreensão do então presente. A tarefa da história e do historiador 
não se encontrava vinculada apenas ao presente, como também aos componentes dinâmicos da vida comum, como bem explicita A. A. Assis:

Ele [Droysen] via a história como fundamento do direito, tanto constitucional quanto ordinário, e portanto, as normas jurídicas de uma nação não deveriam ser derivadas artificialmente de ideias abstratas, tais como a razão ou o direito natural, mas derivariam de seu próprio modo de vida histórico, seus usos e costumes. (p. 147)

A exemplaridade, premissa dos antigos, e a singularidade, característica da modernidade, refletem-se na intricada relação entre metodologia, didática, historiografia e ativismo político na Alemanha do século XIX.

O autor, Arthur Alfaix Martins, presenteia o leitor com um apêndice de grande valor para a pesquisa historiográfica, bem como para promover um melhor conhecimento da extensão da obra de Droysen. Trata-se de uma nota bibliográfica riquíssima em informações e comentários elucidativos a respeito de seu conteúdo.

Trata-se de um livro referencial para o (re)conhecimento da obra de Droysen enquanto teórico e pensador da história: nos deparamos com a análise e a compreensão do "pensamento histórico" como elementos constantes da escrita da história. A construção da teoria é apresentada com enfoque aos aspectos didático, histórico-filosófico e político - todos componentes daquilo que se estruturará como base para a construção do conhecimento histórico e sua metodologia. E mais interessante ainda é podermos acompanhar a exposição dessas ideias ao mesmo tempo que a incursão aos elementos subjetivos que permeiam a hermenêutica historiográfica se mostram plenos de atualidade. Como bem resume o autor, "a ação humana pode se beneficiar com o enriquecimento da capacidade individual de percepção da historicidade inerente às condições da ação no presente" (p. 181).

Cabe aqui também ressaltar a importância deste trabalho dentro do amplo quadro da ausência de publicações de história da historiografia em nosso país. As publicações dentro dessa área sempre foram escassas: as análises e as traduções de textos historiográficos e os estudos críticos são ainda pouco divulgados e valorizados. Esta obra, apesar de escrita em inglês, soma-se a importantes publicações recentes, fruto do sério empreendimento de historiadores como Estevão de Rezende Martins, como A história pensada: teoria e método na historiografia europeia do século XIX, publicada pela Editora Contexto; Lições de história: o caminho da ciência no longo século XIX, de Jurandir Malerba, publicada pela editora FGV; a coletânea de textos organizada por Manoel Salgado, intitulada Livro de fontes da historiografia brasileira, publicada postumamente pela editora da Universidade do Rio de Janeiro, as traduções 
comentadas do Manual de Teoria da História e de Fundamentos de Teoria da História, de Gervinus, ambos elaborados por Sara Baldus e Julio Bentivoglio e publicados pela editora Vozes. Trata-se, sem dúvida, de valiosas fontes textuais para a história da historiografia no Brasil.

\section{Bibliografia}

ASSIS, Arthur Alfaix. What is history for? Johann Gustav Droysen and the functions of historiography. Oxford: Berghahn Books, 2014.

CROCE, Benedetto. La storia come pensiero e come azione. Bari: Laterza, 1938.

DILTHEY, Wilhelm. Einleitung in die Geisteswissenschaften. [S. l.], [s. n.], 1883.

. Der Aufbau der geschichtlichen Welt in den Geisteswissenschaften. Berlin: Verlag der Königlichen Akademie der Wissenschaften, 1910.

NIETZSCHE, Friedrich. Vom Nutzen und Nachteil der Historie für das Leben. Leipzig: Verlag von E. W. Fritzsch, 1874. (Unzeitgemäße Betrachtung, stück II).

POPPER, Karl. The poverty of historicism. Economica, London, vol. 12, n. 46, 1945, p. 69-89.

TROELTSCH, Ernst. Die krisis des historismus. Die Neue Rundschau, Berlin, vol. l, n. 33, 1922, p. 572-590.

. Der Historismus und seine Probleme. Aalen: Scientia Verlag, 1961. (Gesammelte Schriften, stück IV). 